\title{
Analisis Upaya Manajemen Rumah Sakit Dalam Penerapan Budaya Kesehatan dan Keselamatan Kerja (K3) Pasca Akreditasi pada Sebuah RSUD di Kabupaten Semarang
}

\author{
Naela Fadhila*, Sudiro**, Hanifa Maher Denny** \\ *Alumni Magister Ilmu Kesehatan Masyarakat Universitas Diponegoro, **Staf Pengajar Program Magister \\ Ilmu Kesehatan Masyarakat Universitas Diponegoro \\ Email: naelafadhila@gmail.com
}

\section{ABSTRACT}

Occupational Health and Safety was very important to protect employees, patient and visitor from occupational illness and occupational accident. Occupational Health and Safety Standard in Hospital was regulated by Decision of The Minister of Health Number 1087/Menkes/SK/VIII/2010. Ahead of accreditation, management has made many efforts to implemented Occupational Health and Safety in Regional Public Hospital of Semarang District. The achievement of accreditation result was 5 star with $80 \%$ of its passing grade including Occupational Health and Safety. However, the implementation of Occupational Health and Safety culture post accreditation has not yet been well occupied. The research aimed in analyzing the implementation of Occupational Health and Safety culture at a Regional Public Hospital of Semarang District after accreditation process. It is a qualitative research by using observation and depth interview. The interview was performed on hospital employees, the head of hospital's accreditation team, Occupational Health and Safety team secretary, medical services management, patients and visitors. The interview based on the research variable such as employee's assumption, Occupational Health and Safety values, Occupational Health and Safety artifacts and Occupational Health and Safety culture. The result shows that Occupational Health and Safety culture at Regional Public Hospital of Semarang District is not well implemented. Management commitment and good leadership is necessary due to the Occupational Health and Safety culture implementation.

Keywords: Hospital; Management; Occupational Health and Safety culture

\section{PENDAHULUAN}

Kesehatan dan Keselamatan Kerja sangat penting untuk melindungi pekerja, pasien dan pengunjung dari penyakit dan kecelakaan akibat kerja. Standar K3 di Rumah Sakit (RS) diatur dalam Keputusan Menteri Kesehatan Nomor 1087/Menkes/SK/VIII /2010. Menjelang akreditasi, manajemen telah melakukan berbagai upaya untuk melaksanakan K3 di RSUD Kabupaten Semarang, yaitu menyediakan SDM dengan pembentukan tim akreditasi RS yang di dalamnya terdapat Pokja MFK, pembentukan komite K3, menyusun Pengembangan Pedoman, Petunjuk Teknis dan 
Standard Operational Procedure (SOP) K3RS yang sesuai dengan standar, membuat kebijakan K3 kemudian memberikan himbauan kepada karyawan RS untuk membudayakan K3 RS, menyediakan anggaran, mengupayakan peningkatan keterampilan SDM RS dalam menjalankan K3 dengan memberikan pelatihan umum K3RS, pelatihan intern RS, mengijinkan SDM untuk mengikuti pendidikan K3 lebih lanjut. Sumber daya manusia yang terkait dalam implementasi K3 yaitu dokter, paramedis, tenaga kerja non medis, tenaga administrasi, tenaga yang bertugas merawat fasilitas dan sarana RS.

Capaian hasil akreditasi adalah Paripurna Bintang 5, yang artinya lulus semua bab dengan nilai minimal setiap bab $80 \%$ termasuk bidang Kesehatan dan Keselamatan Kerja. Namun, setelah akreditasi masih terdapat beberapa data yang menunjukkan bahwa Kesehatan dan Keselamatan Kerja belum berjalan dengan baik. Data tersebut antara lain $33,33 \%$ petugas kebersihan lupa memakai alat pelindung diri, $30 \%$ petugas medis lupa mencuci tangan dan menggunakan sarung tangan sebelum merawat pasien, 28\% karyawan merokok di lingkungan rumah sakit, $50 \%$ petugas medis dan non medis mengalami penyakit akibat kerja tetapi tidak melapor, 25\% karyawan bagian administrasi nyeri punggung saat bekerja tetapi tidak melapor, hanya $1,79 \%$ insiden kecelakaan kerja yang terlaporkan selama tahun 2016. Penelitian ini bertujuan untuk menganalisis upaya manajemen RS dalam penerapan budaya Kesehatan dan Keselamatan Kerja pasca akreditasi pada sebuah Rumah Sakit Umum Daerah di Kabupaten Semarang.

\section{METODOLOGI PENELITIAN}

Jenis penelitian adalah penelitian kualitatif melalui observasi dan wawancara mendalam. Penelitian dilaksanakan pada bulan Mei tahun 2017 yang berlokasi di RSUD Kabupaten Semarang. Subyek

penelitian meliputi informan utama, yaitu dokter, perawat, apoteker, pranata laboratorium, radiografer, nutrisionis, staf administrasi, petugas kebersihan dan informan triangulasi, yaitu ketua tim akresitasi, sekretaris tim K3, manajer pelayanan medis. Pengumpulan data dilakukan sekaligus pada satu kali kegiatan pengamatan. Pengumpulan data dengan cara wawancara mendalam (indepthinterview), observasi dengan mengggunakan daftar checklist dan telaah dokumen. Pengolahan dan analisis data dilakukan dengan mereduksi data, display data, analisis isi dan pengambilan keputusan.

\section{HASIL DAN PEMBAHASAN}

Manajemen telah memiliki berbagai upaya untuk menerapkan budaya K3 di RSUD Kabupaten Semarang, antara lain membuat kebijakan K3, membentuk komite K3 RS, membentuk tim akreditasi RS, menyusun program kerja K3 RS, menyusun pedoman dan SOP K3 RS, menyediakan SDM dan anggaran, serta melakukan koordinasi K3.Keberhasilan budaya K3 dilihat dari 3 aspek, yaitu asumsi, nilai-nilai dan artefak. Asumsi karyawan tentang K3 di RSUD Kabupaten Semarang sudah baik. Mereka mengetahui bahwa K3 untuk melindungi diri sendiri dan pasien agar tidak tertular penyakit, mengerti apa yang aman dan tidak aman dalam bekerja, apa yang harus mereka waspadai, siapa saja yang berisiko, APD apa saja yang harus digunakan saat bekerja, kapan dan bagaimana cara menggunakannya.

"Saya yakin K3 untuk melindungi diri
seperti memakai APD biartidak tertular
penyakit karena kalau saya sedang
membersihkan muntahan pasien tidak
pakai sarung tangankan bias ketularan
penyaki tpasien”.” (IU 8)
“...saya kira mereka yakin kalau sarung
tangan dan masker itu untuk melindungi
karyawan dan juga pasien. Saya juga yakin
kalau dokter dan perawatnya pakai


sarungtangan dan masker, pasiennya juga terlindungi. Biar lebih bersih”. (IT 7)

Nilai-nilai K3 dapat dinilai berdasarkan perilaku, orang-orang yang mendukung $\mathrm{K} 3$, software dan hardware. Perilaku K3 karyawan RSUD Kabupaten Semarang belum semuanya baik. Masih terdapat karyawan yang tidak menggunakan APD sesuai SOP dengan alasan lupa atau tidak nyaman.

"...ya pernah juga lupa, sering sih. Kadang lupa pakai masker. Kalau lagi panas juga kadang ga pake masker ga pakai sarung tangan". (IU 8)

“...biasanya perawat sering lupa cuci tangan kalau mau ke pasien, tapi setelah dari pasien pasti cuci tangan. Sering juga mereka tidak pakai sarung tangan waktu mau melepas selang infus pasien yang mau pulang, padahal itu kan masih berisiko untuk mereka”. (IT 1)

Namun, komunikasi dalam K3 di RSUD Kabupaten Semarang sudah baik. Mereka saling mengingatkan apabila ada teman yang tidak menggunakan APD. Manajemen juga telah melakukan sosialisasi tentang K3 setiap apel pagi diikuti simulasi.

“....pernah juga lupa pakai sarung tangan waktu ada pasien muntah. Lha gimana, kalau ga cepet nanti keburu muntah malah kotor semua lantainya. Waktu itu ya sudah diingatkan teman saya". (IU 8)

“....setiap apel pagi selalu diingatkan soal K3. ” (IT 3)

Pelaksanaan K3 di RSUD Kabupaten Semarang disupervisi oleh pihak manajemen.Namun, belum konsisten dalam menegakkan sanksi bagi karyawan yang belum sesuai dengan aturan. Tidak ada reward dan punishment dalam supervisi K3.
Apabila ada karyawan yang belum sesuai aturan, manajemen hanya mengingatkan.

"Iya, kadang-kadang ada yang ngawasin
kerja. Kalau ada teman yang tidak pakai APD
diingatkan oleh manajemen". (IU 8)
"Tidak ada sanksi untuk karyawan yang tidak
melaksanakan K3 sesuai SOP, hanya
diingatkan saja. Sulit untuk menerapkan
punishment disini. Pernah sih diterapkan
punishment, tapi tidak berjalan". (IT 3)

RSUD Kabupaten Semarang sudah melengkapi software dalam K3 dengan membuat SOP pada masing-masing bagian dan memberikan pendidikan dan pelatihan K3 kepada karyawan.

"Iya, kalau kerja ada SOP nya, misalkan harus pakai sarung tangan sama masker gitu”. (IU 8)

"Semua bagian sudah ada SOP nya. Setiap karyawan harus tau. Dari awal mereka kerja juga sudah wajib diperkenalkan”. (IT 3)

"Semua karyawan di laboratorium ini sudah pernah mengikuti pelatihan K3. Karyawan di ruangan lain juga sepertinya sudah pernah ikut, cuma waktunya aja yang beda-beda". (IU 4)

"Pelatihan K3 untuk semua karyawan yang kerja disini, tapi dilakukan secara bergantian. Pelatihan K3 ini mengutamakan karyawan yang pekerjaannya berhubungan langsung dengan pasien”. (IT 2)

Demikian pula dengan hardware K3 di RSUD Kabupaten Semarang, pihak manajemen telah melengkapi dan mencukupi APD pada setiap bagian di rumah sakit sesuai kebutuhan.

"APD nya cukup sih. Sarung tangan dan masker selalu ada. Sebelum habis sudah distok lebih dulu”. (IU 4)

"APD itu penting. Jadi harus selalu cukup dan memadai. Kepala bagian di masing-masing ruangan punya tanggungjawab untuk memantau kelengkapan APD". (IT 3) 
berdasarkan Keputusan Direktur RSUD Kabupaten Semarang Nomor 01/11/PROG/IX/2015 tentang Program Kesehatan dan Keselamatan Kerja (K3) di RSUD Kabupaten Semarang dan Keputusan Direktur RSUD Kabupaten Semarang Nomor 445/II/11.04/IX/2015 tentang Pedoman Penyelenggaraan K3 di RS. Berdasarkan hasil observasi, artefak yang berkaitan dengan K3 di RSUD Kabupaten Semarang sudah lengkap. Namun, masih ada yang belum sesuai, antara lain belum ada evaluasi limbah dari outlet IPAL ke BPLHD (4x/tahun) karena baru berjalan 3 tahun; evaluasi pengukuran suhu dan kelembaban udara tidak dilakukan setiap bulan karena keterbatasan dana; ketersediaan masker untuk pasien sering kosong karena persediaan tidak sebanding dengan kebutuhan pasien dan pengunjung; stop kontak tidak ada pengaman tetapi letaknya agak tinggi; masih terdapat akses jalan menanjak yang tanpa pegangan karena sedang proses perbaikan.

\section{KESIMPULAN}

RSUD Kabupaten Semarang merupakan rumah sakit tipe $\mathrm{C}$ dengan luas bangunan $6.130 \quad \mathrm{~m}^{2} / 8.204 \mathrm{~m}^{2}$. Pihak manajemen rumah sakit telah melakukan berbagai upaya untuk menerapkan K3, antara lain membuat kebijakan K3, membentuk komite K3 dan tim akreditasi RS yang di dalamnya terdapat Pokja MFK, menyusun program kerja K3 dan pedoman K3 RS, menyediakan SDM, anggaran dan melakukan koordinasi K3. Subyek penelitian terdiri atas 10 orang informan utama dan 8 orang informan triangulasi.

Asumsi karyawan RSUD Kabupaten Semarang mengenai K3 sudah baik. Mereka yakin dan paham tentang K3 di RS. Namun, dalam pelaksanaan praktek K3, tidak semua karyawan berperilaku baik sesuai asumsi mereka.
Manajemen mengupayakan nilai-nilai K3 di RSUD Kabupaten Semarang menjadi baik dengan menyediakan orang-orang yang mendukung K3, yaitu tim K3 RS, tim akreditasi RS dan supervisor/pengawas pelaksanaan K3, tetapi belum optimal Karena tidak bias focus pada tanggungjawab mereka dalam K3. Selain itu, manajemen juga tidak konsisten terhadap punishment yang diberikan bila karyawan tidak melaksanakan K3 dengan baik. Manajemen juga sudah melengkapi software dengan memberikan pendidikan dan pelatihan $\mathrm{K} 3$, menyusun pedoman $\mathrm{K} 3$ dan SOP; serta melengkapi hardware dengan menyediakan dan mencukupkan APD di RS. Namun, dalam hal perilaku K3, masih ada sebagian karyawan RS yang belum terbiasa untuk berperilaku K3 dengan benar.

Artefak yang berkaitan dengan K3 di RSUD Kabupaten Semarang menjadi bagian dari upaya manajemen untuk menerapkan budaya K3 di RS. Artefak yang ada di RSUD Kabupaten Semarang disusun berdasarkan Keputusan Direktur RSUD Kabupaten Semarang Nomor 445/II/11.04/IX/2015 tentang Pedoman Penyelenggaraan K3 di RS. Berdasarkan observasi, artefak yang bekaitan dengan K3 sudah baik, tetapi masih ada yang belum sesuai.

Peneliti menyimpulkan bahwa sesungguhnya budaya K3 di RSUD Kabupaten Semarang belum berjalan. Pihak manajemen Rumah Sakit sudah melakukan berbagai upaya untuk menerapkan budaya K3, namun belum konsisten. Oleh karena itu, dibutuhkan pembenahan terhadap komitmen dan leadership agar menjadi lebih baik dan lebih focus untuk menerapkan budaya K3 di rumah sakit.

\section{DAFTAR PUSTAKA}

1. Luthans, F. Organizational Behavioral. Twelfth Edition. New York: McGraw-Hill; 2011.

2. Kreitner, R. \& A. Kinicki. Organizational Behavior. 10th Edition. New York: NY McGraw-Hill/Irwin; 2013. 
3. Schein, E.H. Organizational Culture and Leadership. Third Edition. . San Francisco: Jossey-Bass Publishers; 2004.

4. Menkes. Keputusan Menteri Kesehatan Republik Indonesia Nomor 432/Menkes/SK/IV/2007 Tentang Pedoman Manajemen Kesehatan dan Keselamatan Kerja (K3) di Rumah Sakit. In: Kesehatan, ed. Jakarta; 2007.

5. RI P. Undang-Undang Republik Indonesia Nomor 36 Tahun 2014 Tentang Kesehatan. Jakarta; 2014.

6. DEPKES. Riset Kesehatan Dasar 2013. Diaksesdari http://depkes.go.id/download/riskesdas20 13/hasil\%20Riskesdas\%202013.pdf tanggal 12 maret 2015

7. Grahanintyas, D., Wignjosoebroto, S. dan Latiffanti, E. Analisa Keselamatan dan Kesehatan Kerja (K3) dalam Meningkatkan Produktivitas Kerja (Studi Kasus: Pabrik The Wonosari PTPN XII). Jurnal Teknik Pomits. 2012; Volume 1(1): 1-6.

8. Anies. Penyakit Akibat Kerja. Cetakan Pertama. Jakarta: PT. Elex Media Komputindo; 2005.

9. European Agency for Safety and Health at Work. Occupational Safety and Health Culture Assesment - A Review of Main Approaches and Selected Tools. 2011.

10. Sue Cox \& RhonaFlin. Safety culture: Philosopher's stone or man of straw?, Work \& Stress. 1998; 12:3, 189-201, DOI: $10.1080 / 02678379808256861$.

11. Sulistyawati, Anggraini Budi. Analisis Kesiapan Manajemen Rumah Sakit Dalam Implementasi K3 Untuk Menghadapi Akreditasi di Sebuah RSUD Kabupaten Semarang Tahun 2016 (Tesis). 2016

12. Husni, Lalu. 2005. Hukum Ketenagakerjaan Indonesia .Edisi Revisi. CetakanKelima. Raja Grafindo Persada: Jakarta.
13. Kartikawati, VSV. Analisis Kinerja K3 Pasca Akreditasi di RSUD Sunan Kalijaga Demak (Tesis). 2008.

14. Kamila, Izda. Analisis Pelaksanaan Budaya Keselamatan Pasien Pada Tenaga Perawat di IGD RSUD X di Jawa Tengah (Tesis). 2015.

15. Bungawati A. Penerapan Kesehatan dan Keselamatan Kerja Pada Petugas Penanganan Sampah di Rumah Sakit Kota Palu (Tesis). 2009.

16. Rahayuningtyas PW, Hariyono W. Penerapan Manajemen Keselamatan dan Kesehatan Kerja (MK3) di Instalasi Gawat Darurat RSU PKU Muhammadiyah Yogyakarta (Tesis). 2011.

17. Cushway, Barry and Lodge Derek. Organizational Behaviour And Design. New Delhi: Crest Pub House; 2004.

18. Lako, Andreas. Kepemimpinan dan Kinerja Organisasi. Isu, Teori, danSolusi. Yogyakarta: Amara Books; 2004.

19. Siagian, Sondang P. Organisasi, Kepemimpinan dan Perilaku Administrasi. Jakarta: PT. Gunung Agung. 1986.

20. Swayne, Lina E., et al. Strategic Management of Health Care Organizations. Fifth Edition. British: Blackwell Publishing; 2006.

21. Antonsen, S. Safety Culture: theory, method and improvement. Ashgate Pub Co. 2009; 172 pp.

22. Guldenmund, F.W. Understanding and Exploring Safety Culture. Thesis (PhD). Delft University. The Netherlands. 2010. Available in English at: http://repository.tudelft.nl/view/ir/uuid\%3 A30fb9f1c-7daf-41dd-8a5c-b6e3acfe0023/

23. ILO (International Labour Organization). Keselamatan dan Kesehatan Kerja di TempatKerja. Sarana untuk Produktivitas. Pedoman pelatihan untuk manajer dan pekerja. Modul Lima. Jakarta: SCORE; 2013. 
24. Menkes. Peraturan Menteri Kesehatan Republik Indonesia Nomor 1045/MENKES/PER/XI/2006 Tentang Pedoman Organisasi Rumah Sakit di Lingkungan Departemen Kesehatan. In: Kesehatan, ed. Jakarta; 2006.

25. Neal, A, Griffin, M. A \& Hart, P.M. The Impact of Organizational Climate on Safety Climate and Individual Behaviour. Safety Science. 2000;34. 99-109.

26. Hamaideh, Shaher H. Safety Culture Instrument: A Psychometric Evaluation. University of Cincinnati Hayes, BE.,Perander, J., Smecko, T. \& Trask, J. (1998). Measuring perceptions of workplace safety: Development and validation of the work safety scale. Journal of Safety Research. 2004; Vol. 29, No.3. pp145-161.

27. Gershon, R. M., Karkashian, C. D., Grosch, J. W, Murphy, L. R., EscamillaCejudo, A.,Flanagan, P. A., Bernacki, E., Kasting, C., Martin, L. Hospital Safety Climate and its Relationship With Safe Work Practices and Workplace Exposure Incidents. American Journal of Infection Kontrol. 2000; 28, 211-221.

28. Health and Safety Commission (HSC). ACSNI Study Group on Human Factors. 3rd Report: Organizing for Safety. London (UK): HSC; 1993.

29. Menkes. Peraturan Menteri Kesehatan Nomor 012 Tahun 2012 tentang Akreditasi Rumah Sakit. In: Kesehatan, ed. 2012.

30. Jayanti AIBWS. Analisa Komitmen Manajemen Rumah Sakit (RS) Terhadap Keselamatan dan Kesehatan Kerja Pada RS Prima Medika Pemalang. Jurnal Kesehatan Masyarakat (e-Journal). 2014 Jan; 2:1.Available from:URL:http://ejournals1.undip.ac.id/index.php/jkm

31. Rahma DPA. Akreditasi Rumah Sakit, Pengakuan Atas Kualitas Layanan.
Majalah Dental \& Dental Edisi SeptemberOktober 2012. Jakarta; 2012.

32. Departemen Kesehatan Republik Indonesia. Akreditasi Rumah Sakit. In: Kesehatan, ed. 2008.

33. Ester, Saranga. Analisis Efisiensi Proses Layanan dan Kualitas Pelayanan Rumah Sakit: Penerapan Data Envelopment Analysis (DEA) dan Model Servqual (GAP 5) (Tesis). 2000.

34. Wijono, Djoko. Manajemen Mutu Pelayanan Kesehatan. Teori Strategi dan Aplikasi. Surabaya: Airlangga Univesity Press; 2000.

35. Poerwani, SK dan Evie Sopacua. Akreditasi Sebagai Upaya Peningkatan Mutu Pelayanan Rumah Sakit. Buletin Penelitian Sistem Kesehatan. 2006; Vol. 9 No.3: 125-133.

36. Patilima, Hamid. Metode Penelitian Kualitatif. Malang: UMM Press; 2010.

37. Guldenmund, F.W. Understanding and ExploringSafety Culture. Thesis (PhD). Delft University. The Netherlands. 2010. Available in English at: http://repository.tudelft.nl/view/ir/uuid\%3 A30fb9f1c-7daf-41dd-8a5c-b6e3acfe0023/

38. Direktur. Keputusan Direktur Rumah SakitUmum Daerah Ungaran Kabupaten Semarang Nomor: 445/IV/9.12/I/2015 tentang Pemberlakuan Panduan Alat Pelindung Diri (APD). Ungaran; 2015.

39. Direktur. Keputusan Direktur Rumah Sakit Umum Daerah Ungaran Kabupaten Semarang Nomor: 01/11/PROG/IX/2015 Tentang Program Kesehatan dan Keselamatan Kerja (K3). Ungaran; 2015.

40. Direktur. Keputusan Direktur Rumah Sakit Umum Daerah Ungaran Kabupaten Semarang Nomor: 445/II/11.04/IX/2015 Tentang Pedoman Kesehatan dan Keselamatan Kerja (K3). Ungaran; 2015.

41. RI P. Undang-UndangRepublik Indonesia Nomor 36 Tahun 2009 Tentang Kesehatan. Jakarta; 2009. 
42. Direktur. Keputusan Direktur Rumah Sakit Umum Daerah Ungaran Kabupaten Semarang Nomor: 445/IV/9.12/I/2015 Tentang Pemberlakuan Panduan Alat Pelindung Diri (APD). Ungaran; 2015. 